\title{
Alergênicos alimentares: avaliação do cumprimento da legislação de rotulagem
}

\section{Food allergens: assessment of compliance with labeling legislation}

\author{
Melina Lys Valeriano Silva1; Geoffroy Roger Pointer Malpass²; Mônica Hitomi Okura*3; \\ Ana Claudia Granato Malpass*4
}
${ }^{1}$ Aluno do Programa de Mestrado Profissional em Inovação Tecnológica, Universidade Federal do Triângulo Mineiro, Uberaba, Minas Gerais, Brasil. E-mail: melinalys@hotmail.com
*Professor do Programa de Mestrado Profissional em Inovação Tecnológica, Universidade Federal do Triângulo Mineiro, Uberaba, Minas Gerais, Brasil.
2 Orcid: https://orcid.org/0000-0002-0036-5750. E-mail: geoffroy.malpass@uftm.edu.br
${ }^{3}$ Orcid: https://orcid.org/0000-0002-9875-9378. E-mail: monica.okura@uftm.edu.br
${ }^{4}$ Orcid: https://orcid.org/0000-0001-6487-1225. E-mail: ana.malpass@uftm.edu.br

\begin{abstract}
RESUMO: A prevalência de alergias alimentares tem aumentado nos últimos anos devido à modificação dos hábitos alimentares. Alergia alimentar é uma reação adversa que ocorre quando o organismo reconhece o alimento como uma entidade agressora ao organismo mediada por mecanismos imunológicos. A rotulagem é a principal ferramenta de informação entre o consumidor e o produto. $O$ presente trabalho teve por objetivo avaliar se a RDC n. 26 de 02/07/2015 está sendo devidamente aplicada pelos fabricantes de alimentos. Para tanto utilizou-se uma pesquisa qualitativa sob o ponto de vista descritivo. Realizou-se visitas aos principais supermercados de Uberaba para avaliar os produtos quanto a legislação de rotulagem para alergênicos alimentares. Conclui-se que a informação no rótulo do alimento é muito importante, levando em conta que quem sofre com a alergia tem uma segurança maior quando a informação é clara, objetiva e legível, já que a prevenção é a única forma de proteção da alergia alimentar. A legislação brasileira de advertência de rotulagem de alergênicos alimentares mostrou-se comprometida, trazendo uma linguagem mais clara e de fácil acesso aos consumidores. $\mathrm{O}$ resulto foi satisfatório para a maioria dos itens analisados quanto ao cumprimento das diretrizes exigidas.
\end{abstract}

Palavras-chave: alergênicos, alimentos industrializados, RDC 26, rótulos.

ABSTRACT: The prevalence of food allergies has increased in recent years due to changes in eating habits. Food allergy is an adverse reaction that occurs when the body recognizes food as an aggressive entity mediated by immunological mechanisms. Labeling is the main tool between the consumer and the product. The present work had the objective of evaluating if the labelling norm n. 26 of 2015/07/02 is being properly applied by food manufacturers. In this study a qualitative research approach was employed from a descriptive point of view. Visits were made to the main supermarkets in Uberaba to evaluate the products regarding the labeling legislation for food allergens. It can be concluded that the information on the food label is very important, taking into account that allergy sufferers have greater security when the information is clear, objective and readable, since prevention is the only way to protect against food allergy. Brazilian food labeling legislation for allergens provides clear language and is of easy access for consumers. The result was satisfactory for the majority of the items analyzed in complying with the required guidelines.

Keywords: allergens, industrialized foods, RDC 26, labels. 


\section{INTRODUÇÃO}

Em todas as idades, a alimentação é considerada muito mais do que uma necessidade básica para a sobrevivência do indivíduo e da espécie, pois além de suprir os nutrientes necessários ao crescimento, desenvolvimento e manutenção de funções fisiológicas, envolve aspectos importantes do relacionamento psicossocial. A modificação progressiva dos hábitos alimentares com a introdução de novos alimentos e com a utilização crescente de produtos processados industrialmente criou novos problemas nesta área. Assistimos assim ao aparecimento de novas alergias alimentares e confrontamo-nos com a ocorrência de reações, muitas vezes graves, relacionadas com a ingestão inadvertida de alérgenos em alimentos industrializados (ALMEIDA et al., 1999).

A alergia alimentar (AA) é uma reação de saúde adversa que ocorre quando o sistema imunológico reconhece erradamente um alimento como uma entidade agressora ao organismo. A fração desse alimento que é responsável pela reação alérgica denominase alérgeno. Pelo menos 5 em cada 100 crianças sofrem de AA e acredita-se que nos adultos a prevalência seja mais baixa, entre 3 a $4 \%$ (NUNES et al., 2012). Ainda segundo Nunes et al. (2012), as manifestações clínicas da reação alérgica podem variar de moderadas a graves podendo, em alguns casos, ser fatais. Os sintomas surgem rapidamente, entre alguns minutos até duas horas após a ingestão do alérgeno e podem incluir manifestações cutâneas, respiratórias, gastrointestinais e cardiovasculares. Os alérgenos alimentares mais comuns responsáveis por até $90 \%$ de todas as reações alérgicas são a proteína do leite de vaca, o ovo, amendoim, trigo, soja, peixes e frutos do mar, além de nozes (PEREIRA; MOURA; CONSTANT, 2008).

Um movimento de mães consumidoras que tinham em comum o problema de $A A$ com seus filhos criou a campanha "Põe no Rótulo", que contribuiu para a Diretoria Colegiada da Agência Nacional da Vigilância Sanitária (ANVISA) iniciar o processo de regulamentação da declaração obrigatória destas substâncias no rótulo dos produtos alimentícios alergênicos a fim de proteger a saúde do consumidor (GUEDES, 2016). Esse movimento foi de suma importância e levou a ANVISA a aprovar em junho de 2015 uma norma determinando que as indústrias de alimentos e bebidas coloquem nos rótulos de seus produtos a presença de ingredientes com maior potencial de causar alergias. Essa norma ainda prevê que as empresas informem a possibilidade de contaminação cruzada dos alimentos, durante toda a cadeia produtiva (desde a fabricação até o armazenamento) por produtos que possuem substâncias alérgenas em sua composição, podendo ter diversas origens: compartilhamento de linhas de produção, utilização de mesmos equipamentos e utensílios, falhas operacionais e de manipulação. Através dos rótulos dos alimentos o consumidor consegue definir se o produto é viável ou não para sua alimentação. Visto que a exclusão do alimento é a única medida de prevenção. E, com isso, o hábito de ler rótulos deve ser incentivado com uma linguagem clara e de fácil acesso. Essa política deve ser desenvolvida pelo governo, escolas, organizações não governamentais, órgãos de saúde pública, universidades, indústrias, para que toda a comunidade deve estar atenta aos dizeres de rotulagem.

Assim sendo, este trabalho teve como objetivo avaliar se a RDC n. 26 de 02 de julho de 2015 (BRASIL, 2015) para rotulagem de alimentos vem sendo adotada corretamente pelos fabricantes de produtos alimentícios, avaliando os rótulos de alimentos que são consumidos por crianças nos supermercados na cidade de Uberaba-MG. 


\section{REVISÃO DA LITERATURA}

A maioria da população mundial usufrui de diversos alimentos isentos de problemas. No entanto, para uma pequena porcentagem de indivíduos, determinados alimentos podem causar reações adversas. A palavra alergia deriva do grego allan (outro) e ergon (trabalho) (PEREIRA; MOURA; CONSTANT, 2008). Designa-se por AA a reação adversa de saúde que ocorre quando o sistema imunológico reconhece indevidamente um alimento como um agente agressor ao organismo (NUNES et al., 2012).

Bioquimicamente os alérgenos são majoritariamente glicoproteínas, solúveis em água e resistentes à digestão. São reconhecidos pelo sistema imunológico, levando a produção de anticorpos específicos do tipo lgE. Muitas dessas moléculas evidenciam atividade enzimática, o que lhes faculta a capacidade de atravessar a barreira da membrana mucosa. No caso de existir uma sensibilização prévia a um dado alérgeno, o sistema imunológico desenvolve anticorpos específicos para as moléculas alvos. A resposta alérgica inicia-se com a ativação dos mastócitos, levando à liberação de histamina, citocinas, prostaglandinas, entre outras. Este processo desencadeia o aparecimento dos sintomas cuja intensidade varia em função do grau de exposição ao alérgeno em questão (COSTA; OLIVEIRA; MAFRA, 2012). Segundo a forma de indução da reação alérgica ao alimento, este pode ser classificado como: alérgeno de classe I (ingestão; proteínas ingeridas) e de classe II (proteínas inaladas pelo trato respiratório, pólens, reatividade cruzada com epítopos homólogos de alimentos derivados de plantas) (SOLE et al., 2008).

A principal diferença entre AA e intolerância alimentar (IA) é o tipo de resposta que o organismo tem quando está em contato com o alimento. Na alergia há uma resposta imunológica imediata, isto é, o organismo cria anticorpos como se o alimento fosse um agente agressor e, por isso, os sintomas são generalizados. Já na IA o alimento não é digerido corretamente, sendo a causa, a carência de uma enzima que processaria certo nutriente. Dessa forma, os sintomas surgem, principalmente, no sistema gastrointestinal. Um exemplo, deficiência da lactase, a lactose não é digerida e atrai água ao intestino causando diarreia (OLIVEIRA, 2013). Diferente da AA, o aparecimento dos sintomas da IA, normalmente, é dependente da quantidade do alimento ingerido e, geralmente, não é necessária a exclusão total do alimento em questão. Muitos indivíduos toleram inclusive a ingestão de derivados (laticínios, iogurtes etc.) que contêm menos lactose que o leite em si. Diferenciar a AA da IA é fundamental para que pacientes e seus familiares não sejam expostos a dietas restritivas sem necessidade, que muitas vezes implicam também em restrições socioeconômicas e de qualidade de vida. Na presença de sintomas relacionados à ingestão de alimentos, uma consulta médica é muito importante para o diagnóstico correto e tratamento adequado (GASPARIN; TELES; ARAÚJO, 2010).

As AA mais comuns são ao leite de vaca, ovo, amendoim e frutos de casca rija, como as nozes (conhecidos por "frutos secos"), peixe, marisco, trigo e soja, sendo estes alimentos responsáveis por $90 \%$ das reações. Embora com menos frequência, alguns indivíduos são alérgicos a mais do que um alimento sofrendo, portanto, de AA múltipla. Em alguns casos, alimentos diferentes podem induzir respostas alérgicas semelhantes no mesmo indivíduo. Este fenômeno designa-se reatividade cruzada e surge devido às semelhanças estruturais moleculares entre os alérgenos. Por exemplo, a alergia ao camarão pode estar associada a reações alérgicas a outros tipos de crustáceos. Pacientes alérgicos ao amendoim podem não tolerar soja, ervilha ou outros feijões. Existem pequenos cuidados e medidas simples na preparação e produção de alimentos e refeições que podem prevenir a contaminação 
cruzada como: lavar as mãos corretamente em todas etapas do processo, não usar os mesmos utensílios, não utilizar o mesmo óleo de fritura e cuidados na hora de embalar o alimento (NUNES et al., 2012).

Até o momento, não existe um medicamento específico para prevenir a $\mathrm{AA}$. $\mathrm{O}$ tratamento consiste, principalmente, na exclusão do alérgeno da alimentação do indivíduo. A exclusão de um determinado alimento não é tarefa fácil e a exposição acidental ocorre com certa frequência. Os indivíduos com AA grave (reação anafilática) devem portar braceletes ou cartões que os identifiquem, para que cuidados médicos sejam imediatamente tomados quando necessário. O paciente ou seus responsáveis devem estar sempre atentos e verificar o rótulo dos alimentos industrializados buscando identificar nomes relacionados ao alimento que lhe desencadeia a alergia.

No Brasil, a ANVISA é o órgão responsável pela regularização da rotulagem de alimentos industrializados, com o objetivo de garantir produtos de qualidade e com as informações importantes para os consumidores (ANVISA, 2001). O rótulo é a identidade do produto, é a maneira utilizada para indicar a composição do alimento (ARAUJO; BORTOLETTO, 2015). A rotulagem nutricional tem a função de transmitir informações importantes sobre os alimentos para os consumidores. Conforme a RDC n. 259 de 20 de setembro de 2002 da ANVISA, a rotulagem é definida como toda inscrição, legenda, imagem ou toda matéria descritiva ou gráfica, escrita, impressa, estampada, gravada, gravada em relevo ou litografada, ou colada sobre a embalagem do alimento (BRASIL, 2002). De acordo com a ANVISA os rótulos devem conter:

- Lista de ingredientes: informa os ingredientes que compõem o produto e deve estar em ordem decrescente isto é o primeiro ingrediente é aquele que está em maior quantidade no produto.

- Origem: são as informações que identifiquem o fabricante e onde ele foi fabricado. Importante ter a ciência sobre a procedência do produto.

- Prazo de validade: identificar quando o produto foi fabricado e até quando está dentro do prazo para consumo.

- Conteúdo líquido: indica a quantidade total de produto consumido na embalagem. $\mathrm{O}$ valor deve ser expresso em unidade de massa (kg) ou volume (L).

- Lote: é um número que faz parte do controle na produção.

Além disso, de acordo com a ANVISA (2002) os rótulos dos alimentos não devem:

- Apresentar palavras que possam tornar a informação falsa, que possa induzir o consumidor ao erro.

- Demonstrar propriedades que não possuam ou não possam ser demonstradas.

- Destacar a presença ou ausência de componentes que sejam próprios de alimentos de igual natureza.

- Ressaltar, em certos tipos de alimentos processados, a presença de componentes que sejam adicionados como ingredientes em todos os alimentos com tecnologia de fabricação semelhantes.

- Indicar que o alimento possui propriedades medicinais ou terapêuticos ou aconselhar o seu consumo como estimulantes, para melhorar a saúde, para prevenir doenças ou com ação curativa.

As indústrias fabricantes de alimentos e bebidas embalados prontos para oferta ao consumidor estão se adequando à nova legislação que determina a declaração de informação nutricional obrigatória do valor energético, carboidratos, proteínas, gorduras totais, gorduras saturadas, gorduras trans, fibra alimentar e sódio, nos rótulos de alimentos 
e bebidas embalados. As informações nutricionais referem-se ao produto na forma como está exposto à venda e devem ser apresentadas em porções, e medidas caseiras correspondentes, devendo conter ainda o percentual de valores diários para cada nutriente declarado, exceto no caso dos ácidos graxos trans, cujo valor percentual do valor diário não precisa ser declarado.

A falta de regularização de rotulagem, principalmente, para alergênicos alimentares, levou consumidores a se mobilizarem e criarem a campanha "Põe no Rótulo". Essa campanha foi criada por famílias brasileiras de alérgicos alimentares que se uniram pela internet para reivindicar o direito à informação e criaram uma cartilha com informações. $O$ propósito dessa cartilha é conscientizar a população sobre a AA, auxiliando alérgicos e aqueles que zelam por eles a identificar nos rótulos dos produtos os ingredientes que possam acarretar problemas à saúde. Essa pressão levou a ANVISA a aprovar em julho de 2015 a resolução RDC n. 26 (BRASIL, 2015) que dispõe sobre os requisitos para rotulagem obrigatória dos principais alimentos que causam AA.

As dificuldades de compreensão na leitura dos rótulos resultam de alguns fatores: a lista de ingredientes é apresentada em letras muito pequenas, são usadas nomenclaturas diferentes das que estamos acostumados para indicar um item potencialmente alergênico, além da falta de informações sobre o risco de traços de alérgenos que surgem da contaminação cruzada, em alguma fase do processo de produção (SOUZA et al., 2014). Assim, o objetivo da RDC n. 26 (BRASIL, 2015) é garantir que os consumidores tenham acesso a informações corretas, compreensíveis e visíveis sobre a presença dos principais alimentos que causam alergias alimentares na rotulagem dos alimentos embalados. $\mathrm{Na}$ elaboração da resolução foram adotados diversos procedimentos para garantir o tratamento técnico e transparente da matéria e permitir a ampla participação da sociedade. A principal mudança que a RDC n. 26 (BRASIL, 2015) traz é que no rotulo deverá estar escrito de modo destacado a expressão "ALÉRGICOS CONTÉM" (nomes comuns para fácil identificação dos alimentos que causam AA) e quando não for possível garantir a ausência da contaminação cruzada dos alimentos, ingredientes, aditivos alimentares ou coadjuvantes de tecnologia de constar "ALÉRGICOS PODE CONTER" (nomes comuns dos alimentos que causam AA). Outra expressão que também pode ser utilizada nos rótulos é: "ALÉRGICOS CONTÉM DERIVADOS DE" (nome do ingrediente alergênico).

As advertências exigidas devem estar agrupadas imediatamente após ou abaixo da lista de ingredientes e com caracteres legíveis descritos em caixa alta, negrito, cor contrastante com o fundo do rótulo e altura mínima de $2 \mathrm{~mm}$ e nunca inferior à altura de letra utilizada na lista de ingredientes. Essas declarações não podem estar em locais encobertos, removíveis pela abertura do lacre ou de difícil visualização, como áreas de selagem e de torção. Nos casos de embalagens consideradas pequenas (área de painel principal igual ou inferior a $100 \mathrm{~cm}^{2}$ ) a altura mínima nas advertências é de $1 \mathrm{~mm}$.

A resolução se aplica aos alimentos, ingredientes, aditivos alimentares e coadjuvantes de tecnologia embalados na ausência dos consumidores, inclusive aqueles destinados exclusivamente ao processamento industrial e os destinados aos serviços de alimentação. Porém, os seguintes alimentos estão isentos de atender ao disposto na referida resolução:

- Alimentos embalados que sejam preparados ou fracionados em serviços de alimentação e comercializados no próprio estabelecimento.

- Alimentos embalados nos pontos de venda a pedido do consumidor.

- Alimentos comercializados sem embalagens. 
Para auxiliar os portadores da doença celíaca, que é um processo inflamatório autoimune que se manifesta em indivíduos susceptíveis geneticamente em decorrência da ingestão de glúten, foi aprovado pelo Congresso Nacional em 16/05/2013 a lei 10.674 (BRASIL, 2013), que regula a rotulagem de alimentos quem contém glúten em sua composição. Essa lei prevê que deverá conter nos rótulos dos alimentos, assim como, os alérgenos alimentares, a informação destacada nas embalagens "CONTÉM GLÚTEM" ou "NÃO CONTÉM GLÚTEM" de forma legível e visível.

Recentemente, também foi aprovada pela ANVISA a RDC 136, de 08/02/2017 (BRASIL, 2017), resolução que estabelece requisitos para declaração obrigatória da presença de lactose nos rótulos dos alimentos. Sendo definido como lactose o principal açúcar presente no leite de mamíferos. Dessa forma esta resolução prevê que deverá constar nos rótulos as declarações conforme a quantidade de lactose presente no alimento, de acordo com a Tabela 1.

Tabela 1. Regulamentação da lactose nos rótulos dos alimentos

\begin{tabular}{|c|c|}
\hline Quantidade de lactose no alimento & Frase no rótulo \\
\hline Abaixo de $100 \mathrm{mg} / 1000 \mathrm{~g}$ ou $\mathrm{mL}$ & $\begin{array}{l}\text { Zero Lactose, Isento de Lactose, Sem lactose ou } \\
\text { Não Contém Lactose }\end{array}$ \\
\hline De $100 \mathrm{mg}$ até $1 \mathrm{~g} / 1000 \mathrm{~g}$ ou $\mathrm{mL}$ & Baixo Teor de Lactose ou Baixo em Lactose \\
\hline Igual ou acima de $1 \mathrm{~g} / 1000 \mathrm{~g}$ ou $\mathrm{mL}$ & Contém Lactose \\
\hline
\end{tabular}

Fonte: Adaptado de Brasil, 2017.

O limite de 100mg de lactose por produto foi definido seguindo exemplos de outros países, como Alemanha, que já adotam esta regulamentação há bastante tempo e com base nessa experiência esse limite mostra-se seguro para pessoas com intolerância à lactose. Essas declarações devem seguir o mesmo padrão de legibilidade das advertências da RDC $n^{\circ} 26$ dos alergênicos alimentares, não foi estabelecida uma ordem de declaração dessas advertências, portanto. as empresas podem optar por aquela que entenderem mais adequada para as características do seu produto. E os rótulos devem estar adequados quanto a declaração da lactose até fevereiro de 2019. Esse prazo foi estabelecido para que as indústrias e seus fornecedores se adequem às normas e esgotem os estoques atualmente existentes.

\section{MÉTODO}

Esta é uma pesquisa de caráter avaliativo e abordagem quantitativa que verificou a conformidade dos rótulos de 421 produtos alimentícios industrializados, comumente utilizados na alimentação infantil na cidade de Uberaba-MG (Tabela 2), com as normas estabelecidas pela RDC 26/2015, no período de Julho de 2018 - Janeiro de 2019. Os rótulos desses produtos foram fotografados e analisados segundo os critérios preconizados pela RDC 26, como mostra a Tabela 3. 
Tabela 2: Produtos analisados nos supermercados

\begin{tabular}{cc}
\hline Categorias & Quantidade/ marcas variadas \\
\hline Macarrão & 46 \\
\hline Macarrão instantâneo & 35 \\
\hline Bolachas recheadas & 89 \\
\hline Pão de forma & 33 \\
Bolinhos prontos & 29 \\
\hline logurte & 33 \\
\hline Mistura para bolo & 20 \\
\hline Achocolatado em pó & 12 \\
\hline Leite em pó & 5 \\
\hline Pão de queijo congelado & 8 \\
\hline Chocolate & 54 \\
\hline Cereal matinal & 18 \\
\hline Alimentos prontos congelados & 39 \\
\hline TOTAL & 421 produtos \\
\hline
\end{tabular}

Tabela 3: Itens avaliados nos rótulos dos produtos estudados seguindo a RDC 26.

Itens avaliados para análise dos rótulos

Rotulagem para alergênicos (ALÉRGICOS: CONTÉM/ ALÉRGICOS: CONTÉM DERIVADOS DE/ ALÉRGICOS: PODE CONTER)

Declaração com letra em caixa alta

Declaração em negrito

Declaração com letra em tamanho superior a lista de ingredientes

Declaração em local encoberto, de difícil visualização e/ou lacre/torção

\section{RESULTADOS E DISCUSSÃO}

O processo que resultou na aprovação da regulamentação da rotulagem de alergênicos no Brasil foi bastante democrático e transparente. O debate começou em 2014 e contou com reunião presencial, Consulta e Audiência Pública e chegou ao fim em 24 de junho de 2015, quando a Diretoria Colegiada da Anvisa aprovou, por unanimidade, a RDC n. 26 (BRASIL, 2015), cujo texto foi publicado no Diário Oficial em 3 de julho de 2015. A importância dessa resolução foi propor uma melhor qualidade de vida e proteção da saúde dos indivíduos com AA e pela constatação de diversos problemas na transmissão de informações nos rótulos. A principal mudança que a RDC n. 26 (BRASIL, 2015) traz é que no rótulo deverá estar escrito de modo destacado as expressões:

- "ALÉRGICOS CONTÉM" (nomes comuns para fácil identificação dos alimentos que causam AA)

- "ALÉRGICOS: CONTÉM DERIVADOS DE" (nomes comuns dos alimentos que causam $A A)$ 
- "ALÉRGICOS: CONTÉM" (nomes comuns dos alimentos que causam AA) E DERIVADOS".

E quando não for possível garantir a ausência da contaminação cruzada dos alimentos, ingredientes, aditivos alimentares ou coadjuvantes de tecnologia deve constar "ALÉRGICOS PODE CONTER" (nomes comuns dos alimentos que causam AA).

O prazo para os fabricantes se adequarem após a publicação da resolução foi de um ano. Portanto, todos os produtos disponíveis para comercialização, atualmente, devem estar de acordo com a RDC n. 26 (BRASIL, 2015). O não cumprimento das disposições da resolução, geram penalidades aos fabricantes incluindo advertência, inutilização, interdição e/ou multa.

Para avaliar o cumprimento da RDC n. 26 (BRASIL, 2015), foram analisados diversos produtos consumidos por crianças nas prateleiras de supermercados em Uberaba-MG. Alguns produtos foram analisados em maior quantidade devido a maior variedade. Os resultados obtidos através dessa análise podem ser vistos no Gráfico da Figura 1.

Figura 1: Dados referentes à análise dos rótulos de produtos consumidos por crianças em supermercados de Uberaba.

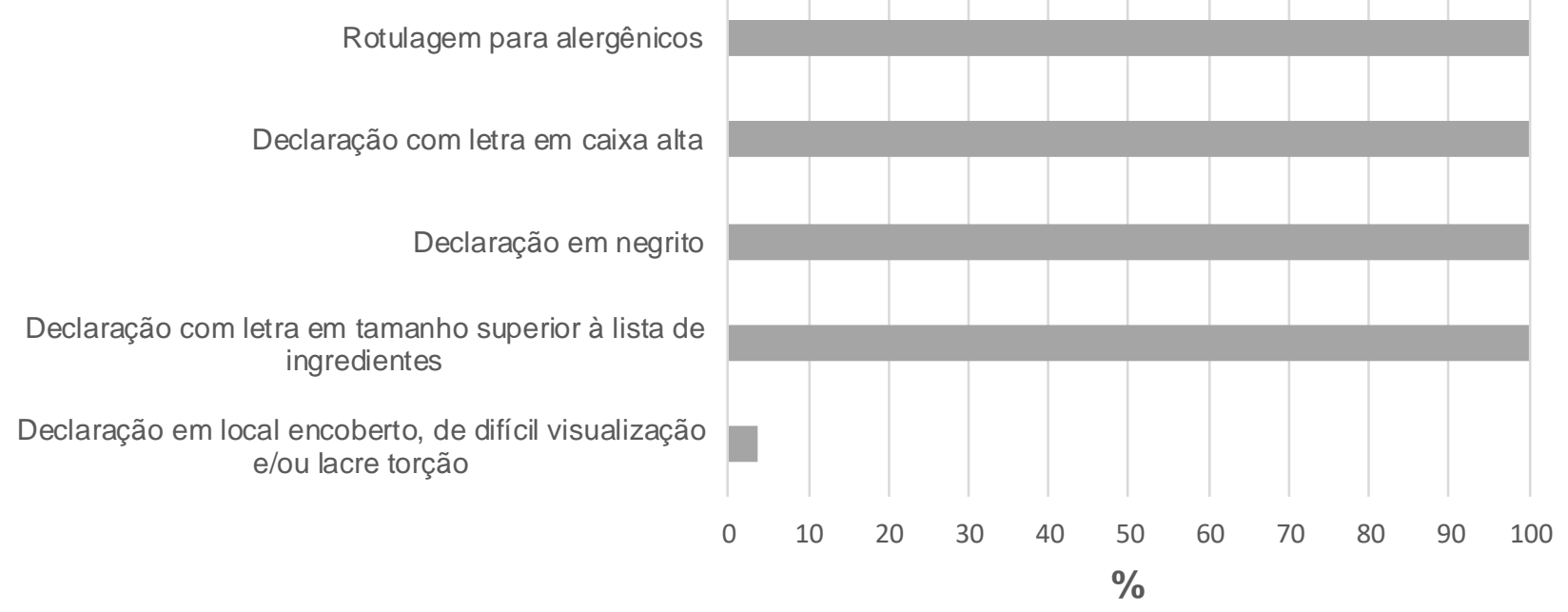

Os resultados da análise dos produtos foram muito satisfatórios quanto a rotulagem para alergênicos, as expressões de advertência foram encontradas em todas as embalagens pesquisadas. Desta forma, há a segurança para aquelas pessoas que realmente necessitam fazer a exclusão de algum alimento da dieta. Além disso, conseguiuse identificar de maneira clara e objetiva as substâncias alérgenas. Na Figura 2 A é possível observar um exemplo de rotulagem de advertência "ALÉRGICOS CONTEM" seguido do nome comum em um dos rótulos analisados. Um outro exemplo de advertência seguindo padrão da RDC n. 26/2015 encontrado nos rótulos analisados foi "ALÉRGICOS: CONTÉM DERIVADOS DE" e "ALÉRGICOS: PODE CONTER" que podem ser observadas na Figura 2 B.

Ainda segundo a legislação, o termo "crustáceos" deve ser declarado seguido do nome comum das espécies entre parênteses, por exemplo "ALÉRGICOS: CONTÉM CRUSTÁCEOS (LAGOSTA)". Na Figura 2 C é possível observar essa expressão de advertência. 
Entretanto, a única não conformidade com a RDC n. 26 (BRASIL, 2015) que foi encontrada em vários produtos foi a declaração em local encoberto, de difícil visualização e/ou lacre/torção. Essa não conformidade foi encontrada em 3,09\% dos rótulos analisados. Apesar de ser um valor baixo, isso demonstra que a RDC 26 ainda não está sendo obedecida nesse quesito por alguns fabricantes. Três exemplos dessa não conformidade podem ser vistos na Figura 2 D e E. Para a embalagem exercer seu papel de informar sendo um canal de comunicação entre indústria e consumidor, deve permitir ao consumidor fazer uso de suas informações. Declarações nas embalagens de alimentos, de difícil acesso oferecem riscos aos consumidores.

Os resultados obtidos neste trabalho foram melhores que os encontrados por Miranda e Gama (2018) que avaliaram a concordância das declarações de alérgenos em 221 rótulos de alimentos industrializados em supermercados de Belo Horizonte e Sabará MG em 2016. As autoras observaram $31,7 \%$ de inadequações nos rótulos analisados, sendo que $48,6 \%$ destes foram classificados como "Declaração inexistente". Entretanto, o trabalho de Miranda e Gama (2018) foi realizado 12 meses após a exigência do cumprimento da RDC 26/2015, assim, provavelmente, os produtores tiveram mais tempo para se adequar e por isso os resultados da presente pesquisa mostram um painel geral melhor.

Figura 2. Exemplos de rótulos com advertência de alergênicos.
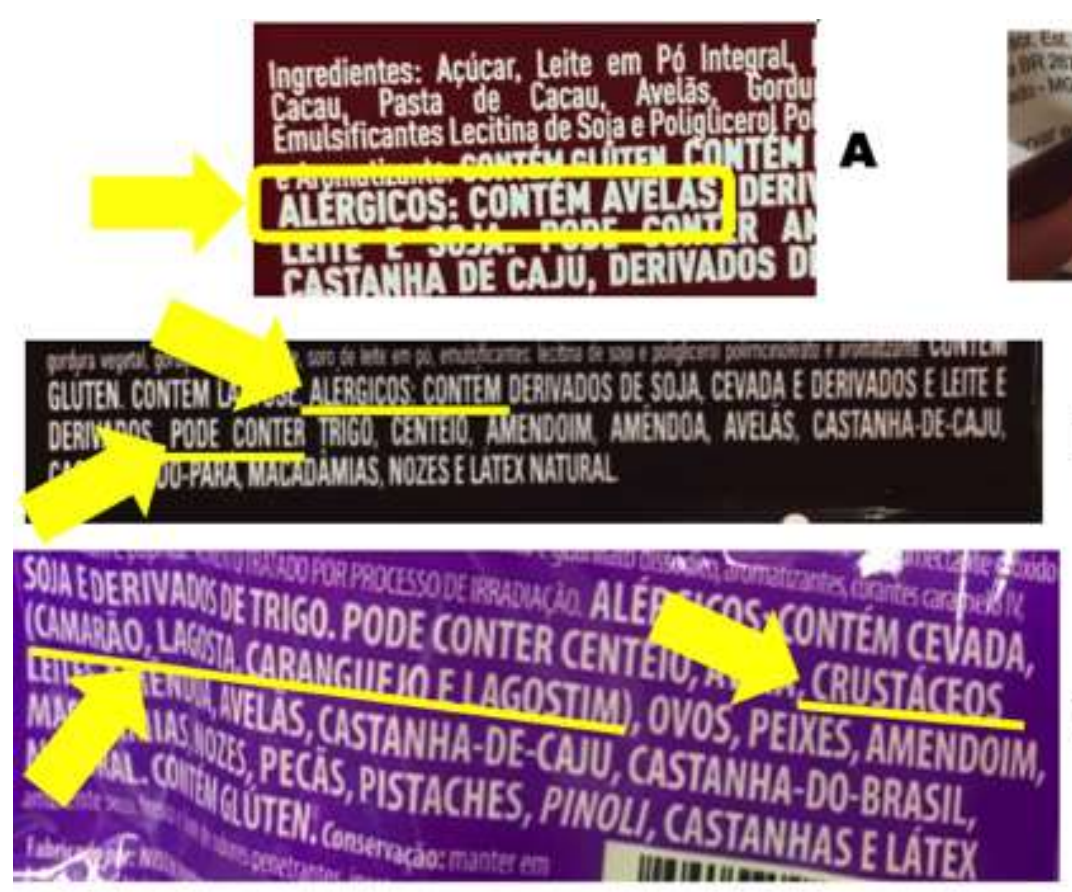

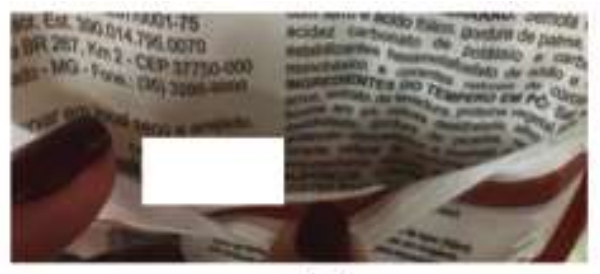

D

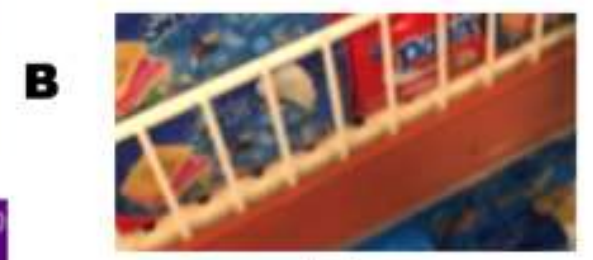

$\mathbf{E}$

O acesso à informação é de suma importância para garantir a saúde do consumidor por isso é importante que o alerta para alérgenos esteja em local de fácil visualização, não encoberto e distante do local de selagem, conforme estabelece a legislação. Desta forma, busca-se evitar mais problemas na compreensão dos rótulos pelos consumidores, uma vez que boa parte destes considera os rótulos de difícil entendimento.

Segundo Marins, Jacob e Peres (2008) a rotulagem de alimentos tem a função de informação, a prática da leitura deve ser exercida pelo consumidor no momento da 
aquisição do produto. Na maioria dos casos, a dificuldade de adquirir o hábito da leitura é constada em relação à compreensão das informações dos rótulos pela população, está dificuldade está relacionada à utilização de uma linguagem técnica e cientifica.

A utilização de uma linguagem de pouca acessibilidade a maioria dos consumidores pode gerar o desinteresse pela leitura dos rótulos. Estas situações podem implicar num descrédito por parte dos consumidores em mudanças que ocorram visando solucionar estes problemas. Qualquer iniciativa visando a auxiliar os consumidores, torna-se inviabilizada se na rotulagem existem falhas, pois a informação deve ser suficientemente clara para atingir a todas as classes de consumidores. Isso pode ser observado nos relatos a seguir (MARINS; JACOB; PERES, 2008):

"As coisas mais relevantes a ser destacadas, não misturar com propagandas e ser mais claro, as propagandas à parte."

"Não sei explicar o que, pois não tenho hábito de ler, é tanto nome complicado que a gente não entende."

"Traduzir o científico para o popular, para as pessoas entenderem."

"Eles usam certos termos que não exemplificam ou explicitam, por exemplo, amido; amido de que; pois para mim é importantíssimo, pois tenho doença celíaca, eu não posso com amido de trigo, aveia e cevada."

"Tem uns nomes malucos, os nomes químicos eu não sei o que é em que quantidade desse elemento e se essa dosagem influencia ou não para uma alergia."

\section{CONCLUSÕES}

Assim conclui-se a importância da criação da RDC n. 26/2015 e sua efetiva implementação para sanar os diversos problemas criados com as dificuldades na interpretação dos rótulos. Os fabricantes de produtos alimentícios para crianças estão de maneira geral, cumprindo as diretrizes exigidas na RDC n. 26/2015. Isso é extremamente importante para o país, pois além de oferecer a devida segurança na leitura dos rótulos com a linguagem mais clara, ainda traz credibilidade aos produtos trazendo mais confiança aos consumidores. Além disso, aumenta as chances de exportação desses produtos a países que tenham o mesmo nível ou maior de exigência e preocupação com os alérgicos e intolerantes.

\section{AGRADECIMENTOS}

\section{FAPEMIG, CNPq e CAPES}

\section{REFERÊNCIAS}

ALMEIDA, M. M.; PRATES, S.; PARGANA, E.; ARÊDE, C.; GODINHO N.; TAVARES, C. et al. Alergia alimentar em crianças numa consulta de imunologia. Revista Portuguesa Imunoalergologia, v.7, n.3, p. 167-171, 1999.

ANVISA. Agência Nacional de Vigilância Sanitária. Rotulagem nutricional obrigatória: Manual de orientação aos consumidores educação para o consumo saudável. Brasília: Ministério da Saúde, ANVISA/UNB, 2001. Disponível em: 
http://www.anvisa.gov.br/alimentos/rotulos/manual_rotulagem.PDF. Acesso em: 26 fev. 2019.

ARAUJO, E.; BORTOLETTO, A. P. Rotulagem de alimentos: avanços e desafios. 2015. Disponível em: http://www.mobilizadores.org.br/wpcontent/uploads/2015/12/

CartilhaRotulagem-de-Alimentos_Avancos-e-Desafios_final.pdf. Acesso em: 26 fev. 2019.

BRASIL. Ministério da Saúde. Agência Nacional de Vigilância Sanitária. Resolução n. 259 de 20 de setembro de 2002. Disponível em:

https://lcqa.farmacia.ufg.br/up/912/o/resoluo_rdc_n_259_2002_-_rotulagem_em_geral.pdf. Acesso em: 26 fev. 2019.

BRASIL. Ministério da Saúde. Agência Nacional de Vigilância Sanitária. Resolução n. 26 de 02 de julho de 2015. Disponível em:

https://www.legisweb.com.br/legislacao/?id=286510. Acesso em: 26 fev. 2019.

BRASIL. Ministério da Saúde. Agência Nacional de Vigilância Sanitária. Resolução n. 136, de 08 de fevereiro de 2017. Disponível em:

http://portal.anvisa.gov.br/documents/10181/2955920/RDC_136_2017_.pdf. Acesso em: 26 fev. 2019.

BRASIL. Presidência da República. Lei n. 10.674, de 16 de maio de 2013. Disponível em: http://www.planalto.gov.br/ccivil_03/leis/2003/110.674.htm. Acesso em: 26 fev. 2019.

COSTA, J.; OLIVEIRA, M. B. P. P.; MAFRA, I. Alergénios Alimentares: o que são, o que provocam e como detetá-los? Química, n. 127, p. 33-38, 2012.

GASPARIN, F. S. R.; TELES, J. S.; ARAÚJO, S. C. Alergia à proteína do leite de vaca versus intolerância à lactose: as diferenças e semelhanças. Revista Saúde e Pesquisa, v. 3, n. 1, p.107-114, 2010.

GUEDES, A. Dados em rótulo podem salvar vida de alérgico. Jornal do Senado.

Especial Cidadania, Brasília Ed. 556. maio 2016. Disponível em:

http://www12.senado.leg.br/cidadania/edicoes/556/dados-em-rotulo-podem-salvar-vidadealergico. Acesso em: 26 fev. 2019.

MARINS, B. R.; JACOB, S. C.; PERES, F. Avaliação qualitativa do hábito de leitura e entendimento: recepção das informações de produtos alimentícios. Ciência e Tecnologia Alimentos, v. 28, n. 3, p. 579-585, 2008.

MIRANDA, C. C. S.; GAMA, L. L. A. Inadequação da rotulagem de alimentos alergênicos: risco para indivíduos com hipersensibilidade alimentar. Demetra: alimentação, nutrição \& saúde, v. 13, n. 3, p. 731-743, 2018.

NUNES, M.; BARROS, R.; MOREIRA, P.; MOREIRA, A.; ALMEIDA, M. M. Alergia alimentar. Portugal. Ministério da Educação e Ciência e Ministério da saúde. 2012. 
OLIVEIRA, V. C. D. Alergia à proteína do leite de vaca e intolerância à lactose: abordagem nutricional e percepções dos profissionais da área da saúde. 2013. $104 \mathrm{f}$. Dissertação (Mestrado em Ciência e Tecnologia do Leite e Derivados) - Universidade Federal de Juiz de Fora, Juiz de Fora, MG, 2013.

PEREIRA, A. C. S.; MOURA, S. M.; CONSTANT, P. B. L. Alergia alimentar: sistema imunológico e principais alimentos envolvidos. Semina: Ciências Biológicas e da Saúde, v. 29, n. 2, p. 189-200, 2008.

SOLE, D.; SILVA, L. R.; ROSÁRIO FILHO, N.; SARNI, R. O. S. Consenso Brasileiro sobre Alergia Alimentar: 2007. Revista Brasileira Alergia e Imunopatologia, v. 31, n. 2, p. 6489, 2008.

SOUZA, C.; PASSADA, D.; RIBEIRO, F.; ANTUNES, J. D.; DIAS, M.; AMARO, S. et al. Põe no rótulo. Cartilha de Alergia Alimentar, Rio de Janeiro, 2014. Disponível em: http://poenorotulo.com.br/CartilhaAlergiaAlimentar_29AGO.pdf. Acesso em: 26 fev. 2019. 